\title{
Investigating Undergraduate Students' Attitudes Towards English Mobile Learning
}

\section{A Case Study of Moroccan University Students}

\author{
${ }^{1}$ O.Omari, ${ }^{2}$ S.Bourekkadi, ${ }^{3}$ K.Slimani, ${ }^{4}$ S.Khoulji, ${ }^{5}$ M.L. Kerkeb \\ ${ }^{1}$ Faculty of Arts and Humanities, Department of English, Moulay Ismail University, Meknes, Morocco; \\ 2,4,5 National School of Applied Sciences, Abdelmalek Essaadi University, Tetuan, Morocco; \\ ${ }^{3}$ Faculty of sciences, Ibn tofail University, Kenitra, Morocco. \\ otmaneomaari@gmail.com
}

\begin{abstract}
The increase of mobile devices, the availability of several features, and the decrease in terms of cost of smartphones made them useful not only for communication, but also for learning. Similarly, the importance of English in higher education makes it one of the most fundamental foreign languages that students want to learn. Many students look for different ways to learn English. Among these ways is Mobile Learning which becomes nowadays a useful tool for language learning due to the evolution of mobile technology. However, little is known about the attitudes of Moroccan students towards English M-learning. Thus, the purpose of this study is to examine the attitudes of using M-learning by university students to learn English. The study involved 286 students representing different universities, levels, and departments. A questionnaire was distributed and interviews were carried out to answer the research questions. Results revealed that university students have positive attitudes towards English M-learning. The total average mean score obtained for the used scale was $M=3.80$. Additionally, the qualitative findings confirmed some results of the quantitative data and displayed other important findings related to feelings and obstacles towards English M-learning. The findings are of great importance for teachers, practitioners, administrators, and websites/apps programmers.
\end{abstract}

Keywords: English; Mobile learning; higher-education; university; Morocco.

\section{Introduction}

The world nowadays is advancing quickly in terms of technology. Everyday we discover new technologies that help us and facilitate our life and our way of living. Education is among the most important fields that know a great amount of technological discoveries. Those discoveries make learning today easier than before and allow many people to reach so much learning materials that were not available in the past. In addition, the increase of technology products such as mobiles, notebooks, tablets, personal computers, electronic translators and others makes the price of these products go down. This allows people to buy these products according to their needs and budget. For instance, mobiles today are everywhere and the majority of people own a mobile or smartphone. More importantly, telecommunication companies make it easy also for mobile owners to access internet through a 3G/4G network facility. Moreover, in many public places Wi-Fi and even Wi-Max are available for free to everyone. All that makes learning easier and 
O.Omari, S.Bourekkadi, K.Slimani, S.Khoulji, M.L. Kerkeb. Investigating Undergraduate Students' Attitudes Towards English Mobile Learning-A Case Study of Moroccan University Students. Transactions on Machine Learning and Artificial Intelligence, Vol 5 No 4 August (2017); p: 381-394

also can be reached everywhere and at any time. In addition, people use these facilities within their portable devices as a learning tool. Today, there is an emerging topic when we talk about learning and technology, which is Mobile Learning (M-Learning).

Nowadays, m-learning is transforming the way students learn in higher education. Students find several ways to access information and can easily find educational resources that enhance their learning process. Meanwhile, according to [1] m-learning is defined as "any educational provision where the sole or dominant technologies are handheld or palmtop devices."(P. 262). This includes mobiles, smartphones, handheld devices, tablets and iPads. Those devices play a crucial role in our daily life and a fundamental role in education when used properly. In fact, there are many ways to use mobiles as an instrument for learning. Many educational applications are available for free and can be used to fulfill different outcomes. For example, on a mobile's online store we can find many applications that help students learn any subject they want. Others can be used to enhance ones Math, Physics, Programming or language skills such as learning English.

On the other hand, due to the fact that English is an important and international language, students are aware now of its importance and tend to look for different ways to develop their English learning skills. In addition, professors and practitioners in the field of education (especially in higher education) encourage students to learn English as it is a language of science that anyone will need while conducting a research and also because it is very important in one's professional life. However, because English is a foreign language in Morocco and some faculties (faculties of science for example) do not include it in their programs, many students look for other ways to learn this crucial language. Meanwhile, the Moroccan government encourages students of all disciplines to learn English, especially students of scientific disciplines. The Moroccan government also launched a program called "Injaz" to support educational development programs. This program provided laptops and tablets with network to students in higher education with low prices. This also allowed students to have their own tablets which are included within the devices that support m-learning. Moreover, this initiative helped students from different social classes to own new technology and use it as a tool of learning. However, this program did not concern all students. Only engineering, master, and PhD students were eligible to benefit from this program once.

In fact, this initiative was made to encourage students to use technology in their learning process; however, there are not enough studies that investigate students' attitudes towards Mobile Learning within the Moroccan context. For that reason and because of the importance of English nowadays, the purpose of this study was to examine students' attitudes towards English Mobile Learning. Thus, the aim of this study was to answer the following 5 research questions:

1. What are students Attitudes towards learning English via Mobile Learning?

2. Are there any differences in students' attitudes in terms of gender, age, major and level of education?

3. Are there any differences in students' attitudes towards English M-learning with regard to their mobile OS and type of Network access?

4. Is there any significant difference among students' attitudes towards English M-Learning in terms of things they use most on their mobiles? 
5. What are students' feelings and perceptions towards the use of English m-learning and obstacles that may prevent them from frequently using this technology?

\section{Mobile Learning}

M-Learning is one of the new and emerging ways of learning using technology. A lot has been said about this topic and students are aware now about it. Some researchers said that m-learning is a simplified way of learning using mobile devices [2, 3]. Additionally, M-learning was defined by [4]as "any sort of learning that happens when the learner is not in a fixed, predetermined location, or learning that happens when the learner takes advantage of the learning opportunities offered by mobile technologies" (p.8). This is to say that M-learning is a way of learning that happens via the use of any kind of mobile devices such as cellphones, tablets, smartphones, PDAs and handheld devices. Meanwhile, the core of the concept is that users can access the information anytime, anywhere from portable devices that they "regard as friendly and personal" (p. 129) [5].

Besides, it is sometimes hard for some people to differentiate between E-learning and M-learning. In fact, though the two concepts differ on their first letters " $E$ " and " $M$ ", they share similarities as for online learning materials, participants (learners), and administrators [6]. However, as stated in [6], E-learning and M-learning differ in terms of mobility. On the other hand, this type of learning using mobiles is divided onto formal and informal. Some studies identify formal M-learning as "where learners are engaging with materials developed by a teacher to be used during a program of instruction in an educational environment, highly structured, institutionally sponsored, and generally recognized in terms of a certificate or a credit upon completion" (p.19)[7]. However, informal M-learning is defined as a learning that is unorganized and unstructured [7]. This means that formal M-learning is used within a professional context to serve several academic outcomes or as a requirement of a course; whereas informal M-learning occurs when learners learn using their mobiles to serve their own desires or motivation to learn something not related to their course requirement. However, it is worth mentioning that there is no decisive definition of informal M-learning and that learners can use informal M-learning to serve an academic formal learning outcome [7]. This is to say that M-learning could be used within formal and informal contexts and can also support lifelong learning [8].

Meanwhile, language learning applications are among the most used and known types in M-learning technology [4]. Several studies [9-11] demonstrated the usefulness of M-learning in language learning because it gives students opportunities and it permits self-learning at any time and any place. However, different factors can affect language learning process. For instance, some of the factors that [12] said to influence language learning include: age, intelligence, anxiety, motivation and attitudes. The latter is known to be one of the most affective variables in language learning as demonstrated in a study by [13]. The study concluded that teachers should develop efficient learning strategies to develop students' attitude towards English.

Another study by [14], which explored attitudes and self-efficacy of college students towards M-learning, revealed that attitude is an important variable in the success of mobile learning. The study indicated also that most investigated students had positive attitudes towards M-learning and that the latter increased their motivation to learn English. Meanwhile, a research by [15] was conducted to explore the attitudes of students and educators towards M-learning technology in 5 different universities from the Arab Gulf region (Oman and UAE). The study demonstrated that most students had positive attitudes towards $\mathrm{M}$ - 
O.Omari, S.Bourekkadi, K.Slimani, S.Khoulji, M.L. Kerkeb. Investigating Undergraduate Students' Attitudes Towards English Mobile Learning-A Case Study of Moroccan University Students. Transactions on Machine Learning and Artificial Intelligence, Vol 5 No 4 August (2017); p: 381-394

learning with no significant differences with regard to gender, major and level of study. However, significant differences were found in terms of students' age, mobile ownership, and country. In terms of country for instance, learners from UAE were favored. Findings of this study indicated also that the integration of M-learning in higher education could be beneficial to the learning pedagogy within the Arab Gulf countries. Additionally, it was confirmed in a study conducted in Nigeria, which focused on finding out the experiences of students' M-learning in higher education, that mobile features inspire and motivate students to learn more [16].

\section{Research Method and Design}

The aim of this study was to investigate students' attitudes towards English Mobile learning. Therefore, a mixed research methods using quantitative and qualitative data were employed. We believe that this method will allow us through quantitative data to explore students' attitudes towards learning English using M-learning technology. It will also allow us to discover students' experiences of using M-learning to learn English through interviewing individuals. This research was conducted in February, during the beginning of the second semester of the academic year 2016/2017.

\subsection{Research context}

The current study was carried out in different Moroccan public universities. Focus was more on students of Sidi Mohamed Ben Abdellah University in Fez and Moulay Ismail University in Meknes. Meanwhile, a copy of the questionnaire was made available online for students from other universities in Morocco. Students from different universities participated in this study, namely from: University Mohamed V (Rabat), Cadi Ayad (Marrakesh), AbdelmalekEssaadi (Tetouan and Martil), and IbnTofail (Kenitra).

\subsection{Population and Sampling}

A total of 286 students from different universities in Morocco participated in this study. Quantitative data were collected using questionnaires which were completed anonymously. The qualitative data were used to answer the first 4 research questions. On the other hand, interviews were used for qualitative data to answer the last research question (question number 5). Questionnaires were administered during February 2017 in two universities (Sidi Mohamed Ben Abdellah and Moulay Ismail University). Sixty-five questionnaires were distributed randomly at Sidi Mohamed Ben Abdellah University and forty at Moulay Ismail University. In addition, an online version of the questionnaire using "Google forms" was created and shared via Social Media to several groups in order to receive responses of students from other universities in Morocco.

Meanwhile, a demographic information form was used to collect students' information such as gender, age, institution, level of education, department, and city. Other variables were added to the demographic information form in order to find out to what extent they may affect students' attitudes toward learning English via M-learning. These variables include questions about smartphone ownership, access to internet, type of operating system (OS), and the most three things students frequently use on their mobiles. Besides, only undergraduate students were asked to fill out the questionnaire voluntarily, which took them less than 5 minutes. They were assured that their information will be kept strictly confidential. 


\subsection{Study instrument}

In order to investigate university students' attitudes towards learning English using mobile learning technology, a survey was adapted from [15]. The authors developed an instrument of 28 items by adopting several items from relevant studies. The instrument was later on reduced to 10 items, tested, and validated by the authors. Due to the specificity of the current study, some additional modifications were carried out. For instance, the term 'Mobile Learning' was used in the current study instead of 'Mobile Technology'. Additionally, the items were modified to fit the English learning context. The word English was added to all items to collect participants' responses concerning their attitudes towards learning English via M-learning. For example, the first item "Mobile technology is a useful tool for my study" was modified to "Mobile Learning is a useful tool for me to study English".

Before the part of the scale, participants were introduced to the meaning of Mobile Learning in order to insure their understanding of the concept. After that, participants were asked to rate how much they agree or disagree with each statement. A five-point-Likert Scale ranging from (1) Strongly Disagree to (5) Strongly Agree was used to collect students' attitudes towards English M-learning. To get a better understanding of students' attitudes towards the use of M-learning to learn English, we interviewed 21 volunteer students (13 females and 8 males). The interviews were conducted with random selection of students. Semi-structured questions were used in the interviews which lasted about 10 minutes each. Besides, due to the modifications made in the scale section, we tested the reliability of the scale using SPSS to determine its validity. Alpha method was used and a coefficient of 0.84 was obtained.

\subsection{Demographic profile}

The demographic results indicate that $47.6 \%$ of the participants were males and $52.4 \%$ were females. Concerning age, the largest age group falls within $16-20$ years represented by $59.8 \%$, participants aged between $21-25$ years represented by $34.6 \%$, whereas the smallest age group was that of participants aged between $26-30$ years represented by $5.6 \%$. On the other hand, Sidi Mohamed Ben Abdellah University in Fez was represented by the largest number of participants $(89,31.1 \%)$. The other institutions were represented as follows: Moulay Ismail University (55, 19.2\%), Mohamed V University (31, 10.8\%), Abdelmalek Essaadi Univeristy in Tetuan (ENSA, Science)(30, 10.5\%), Abdelmalek Essaadi Univeristy in Martil (29, 10.1\%), Ibn Tofail University (28, 9.8\%), and Cadi Ayad (24, 8.4\%).

Participants represented different levels and were from different departments. Most students were second and first year undergraduate students (respectively $42 \%$ and $37.8 \%$ ). In terms of departments, students from the department of English represented more than half of the sampling (52.1\%). Other departments were as follows: Science (9.4\%), Economics (24\%), Physics (10.1\%), French (7.3\%), Math $(4.2 \%)$ and from other departments (8.4\%).

Meanwhile, in response to smartphone ownership, $95 \%$ of participants declared that they have a smartphone. However, only $5 \%$ said that they do not own a smartphone. In terms of the mobile's operating system, $64 \%$ said they have an android, $23 \%$ iOS, $8 \%$ windows, and $5 \%$ said that they have another operating system different from the previously mentioned. Concerning internet access, approximately $38 \%$ of participants said that they access internet through $3 \mathrm{G} / 4 \mathrm{G}$ only, $19 \%$ through Wi-Fi only, $32 \%$ use both $3 \mathrm{G} / 4 \mathrm{G}$ and $\mathrm{Wi}-\mathrm{Fi}$, and about $10 \%$ said that they do not have access to internet. 


\section{Results}

To make the analysis of the findings easy and simple, we will divide the results into two parts. The first part will focus on the findings of the quantitative data (survey), and the second part will display the findings of the qualitative data (interviews).

4.1

Quantitative data

\subsection{1}

What are students Attitudes towards learning English via Mobile Learning?

This research question depends on participants' overall ratings on their attitudes towards English Mlearning scale. The overall mean of the scale was 3.80 with a standard deviation of 0.476 . Students' highest overall score was that of "Mobile Learning is a useful tool for me to study English" ( $M=4.14)$. Table I reveals the mean and standard deviation of each item. As displayed, the other items range from 3.15 to 4.

Table 1. Students' attitudes to English m-learning scale

\begin{tabular}{|c|c|c|}
\hline Items & Mean & Std. Deviation \\
\hline 1. Mobile Learning is a useful tool for me to study English. & 4.14 & 0.603 \\
\hline 2. Mobile Learning can offer me opportunities for English communication and team-working. & 3.97 & 0.505 \\
\hline 3. Mobile Learning can help me find resources related to English learning. & 3.87 & 0.556 \\
\hline 4. Mobile Learning can bring many opportunities to my English learning process. & 3.73 & 0.573 \\
\hline 5. Mobile Learning can help me access English course-material anytime anywhere. & 3.77 & 0.591 \\
\hline 6. Mobile Learning can be an easy way to get feedback and notifications from instructors. & 3.15 & 0.551 \\
\hline 7. Mobile Learning can help me exchange the English course-material with my friends & 3.67 & 0.617 \\
\hline 8. Mobile Apps can help me manage my English Learning. & 3.77 & 0.633 \\
\hline 9. Mobile Learning can help me to do my English coursework. & 3.86 & 0.637 \\
\hline Mobile Learning can help me develop my English learning skills. & 4.07 & 0.590 \\
\hline
\end{tabular}

4.1.1 Are there any differences in students' attitudes in terms of gender, age, major and level of education?

After calculating the means of students' attitudes to learn English via M-learning with regard to gender, we found that there are no differences in students' attitudes in terms of gender. The score of males was $M=3.79$ and the score of females was $M=3.82$. Similar to that, no big differences were found in terms of age. Both students who are aged between 16 and 20 scored a mean of $M=3.82$, and those aged between 21 and 25 scored a mean of $M=3.78$. Meanwhile, first year students ( $M=3.89$ ) showed a slight difference compared with second year and third year undergraduate students (Respectively $M=3.76, M=3.72$ ). Similarly, students fromdepartments of English, French and Physics demonstrated a small difference compared with students representing other departments as displayed in Table III.

4.1.2 Are there any differences in students' attitudes towards English M-learning with regard to their mobile OS and type of Network access?

Again, results demonstrated that there are no big differences in students' attitudes towards learning English via M-learning with regard to the used operating system. The slight difference as demonstrated in 
Table IV is within Android and iOS compared with the other operating systems. On the other hand, students who declared that they access internet using both $3 \mathrm{G} / 4 \mathrm{G}$ network and Wi-Fi scored $(\mathrm{M}=4.05)$ more than those who access internet through 3G/4G only, Wi-Fi only or those who do not have access to internet as demonstrated in Table V.

\subsubsection{Are there any significant differences among students' attitudes towards learning English via M- Learning in terms of things they use most on their mobiles?}

To answer this question, students were asked to select the most three things they frequently use on their mobiles. As demonstrated in Table VI, the majority of students declared that the three things they use most on their mobiles are social networking, instant messaging, and listening to music. In terms of their attitudes to learn English via M-learning and the things they use most on their mobiles, we notice that students who declared that accessing email is one of the most three things they use scored a higher level of attitude $(M=4.14)$. Meanwhile, the other items were about similar ranging from a score of $M=3.61$ to 3.87 .

Table 2. Means according to major

\begin{tabular}{|l|c|c|c|}
\hline Department/Major & Mean & N & Std. Deviation \\
\hline English & 3.98 & 149 & 0.466 \\
\hline Physics & 3.95 & 29 & 0.478 \\
\hline French & 3.91 & 21 & 0.382 \\
\hline Economics & 3.73 & 24 & 0.410 \\
\hline Science & 3.66 & 27 & 0.524 \\
\hline Maths & 3.56 & 12 & 0.536 \\
\hline Other & 3.74 & 24 & 0.417 \\
\hline Total & 3.80 & 286 & 0.476 \\
\hline
\end{tabular}

Table 3. Means according to type of OS

\begin{tabular}{|l|c|c|c|c|}
\hline Type of mobile OS & Mean & $\mathbf{N}$ & Std. Deviation & \% of Total N \\
\hline Android & 3.96 & 184 & 0.472 & $64.3 \%$ \\
\hline los & 3.92 & 64 & 0.494 & $22.4 \%$ \\
\hline Windows & 3.70 & 23 & 0.464 & $8 \%$ \\
\hline Other & 3.57 & 15 & 0.470 & $5.2 \%$ \\
\hline
\end{tabular}

Table 4. Means according to internet access

Table 5. Things students use most on their mobiles and means of their attitudes towards Englishm-learning

\begin{tabular}{|l|c|c|c|c|}
\hline \multirow{2}{*}{ Most used things $^{\text {a }}$} & \multicolumn{2}{|c|}{ Responses } & \multirow{2}{*}{ Percent of Cases } & \multirow{2}{*}{ Attitude Mean } \\
\cline { 2 - 3 } & $\mathbf{N}$ & Percent & & \\
\hline Social Networking & 261 & $30.9 \%$ & $91.3 \%$ & 3.81 \\
\hline Instant messaging & 236 & $28.0 \%$ & $82.5 \%$ & 3.82 \\
\hline Listening to music & 121 & $14.4 \%$ & $42.3 \%$ & 3.65 \\
\hline Searching for information & 91 & $10.8 \%$ & $31.8 \%$ & 3.87 \\
\hline Accessing Email & 54 & $6.4 \%$ & $18.9 \%$ & 4.14 \\
\hline Watching videos/movies & 20 & $2.4 \%$ & $7.0 \%$ & 3.64 \\
\hline Playing games & 20 & $2.4 \%$ & $7.0 \%$ & 3.61 \\
\hline Reading (articles, books...) & 13 & $1.5 \%$ & $4.6 \%$ & 3.80 \\
\hline Other & 27 & $3.2 \%$ & $9.4 \%$ & 3.61 \\
\hline Total & 843 & $100.0 \%$ & $294.8 \%$ & \\
\hline
\end{tabular}

a. Dichotomy group tabulated at value 1 


\subsection{Qualitative data}

As mentioned earlier in the methodology section, 21 volunteer students accepted to participate in the interview. A descriptive analysis is carried out to identify students' attitudes and perceptions concerning learning English using M-learning technology.

\section{Q1: What is your opinion concerning the importance of learning English?}

The first question was about the importance of English in relation to students' field of study and future career. For this question, all participants confirmed that English for them is very important and that they want to enhance their English learning skills. Participants from the department of English said that English is their major, so they are required to look for ways to develop their English skills. On the other hand, participants representing other departments declared that English for them is crucial because they know that they will need it either during their graduate studies or when they want to get a job. Some participants said, "English for me is very important because it will help me find a suitable career after I graduate", "English is very important because it is the language of science, learning this language will help me when I want to conduct my research paper", "Except from the fact that it is a universal language, I have always loved it since I was in high school".

\subsubsection{Q2: What do you think about using your mobile to learn English?}

The second question was about students' perceptions on the use of M-learning technology to learn English. Most participants (17) indicated that this technology is very useful for them and that it can help them learn the language whenever they want and at their ease. Other students said that M-learning to learn English "saves time and money" and "it is a lot of fun". Meanwhile, some students suggested that M-learning would be more interesting and beneficial if teachers afford them with helpful electronic materials. On the other hand, others declared that learning via mobile disturbs them, especially when they are using internet. Table VII demonstrates different opinions of students concerning that question.

Table 6. Students' statements for interview Q2

\begin{tabular}{|l|c|}
\hline \multicolumn{1}{|c|}{ Statements } & Frequency (N=21) \\
\hline Using technology to learn English is very helpful to me. & 17 \\
\hline When I have time, I go online and look for something that will help me learn English. & 13 \\
\hline Learning English via mobile is a lot of fun. & 13 \\
\hline Learning English using my mobile will save me a lot of money. & 11 \\
\hline With mobile, I can get a lot of information quickly and at any time. & 9 \\
\hline $\begin{array}{l}\text { Learning via mobile will be more beneficial if teachers can afford us with useful materials that will } \\
\text { help us. }\end{array}$ & 6 \\
\hline I get distracted when I use my mobile to learn. & 5 \\
\hline I find what I study in class enough. I use my mobile just to check for definitions. & 3 \\
\hline I don't think this is a good idea. & \\
\hline
\end{tabular}




\subsubsection{How do you feel about using your mobile to learn English or to support your English learning course?}

Students in this question were asked to describe their feelings concerning learning English using their mobiles. The majority of participants (14) stated that they have already the previous experience using their mobiles to support their English language learning skills. They also said that they enjoyed a lot learning using their mobiles because it is easy and quick, and also because they do not need to wait for their computers to turn on. Some (12) also said that the use of M-learning to learn English helps them and will help them to develop their language skills especially in terms of listening, reading and vocabulary skills. However, some students (6) declared that they feel anxious because they cannot find useful materials that will enhance their English learning skills.

\subsubsection{Is there anything that makes you sometimes unwilling to use your mobile to learn English?}

To identify obstacles that may prevent learners from using their mobiles to learn English, participants were asked to state anything that makes them hesitating to use their mobiles. As displayed in Table VIII, one of the most reasons that make students do not frequently use or hesitate to use their mobiles to learn English is 'bad network'. Another reason was related to offline mode. Some students said that they cannot have internet network every day, which prevent them from accessing the content frequently. They also added that though there are some applications providing offline mode, they are still limited in terms of content. Meanwhile, some participants declared that most websites and applications do not provide a placement test and this makes it difficult for them to find the appropriate material for their levels.

Meanwhile, some students stated that a lot of advertisements on mobile applications or websites prevent them from trying to learn English via M-learning. One of the students said "When I visit a website and I find a lot of advertisements, I just quit". Another said "Sometimes I visit a website, and when I want to change the task it takes me to another website for advertisement reason".

Table 7. Students' statements for interview Q4

\begin{tabular}{|l|c|}
\hline Statements and reasons & Frequency (N=21) \\
\hline Bad internet network. & 18 \\
\hline Most applications/websites I used donot provide a placement test. & 14 \\
\hline Lack of user feedback feature & 12 \\
\hline Bad design and interface. & 12 \\
\hline Apps do not support offline mode. & 11 \\
\hline Bad app performance (Slow response, long load times, crashes). & 10 \\
\hline A lot of advertisements. & 10 \\
\hline Apps requesting access to private content. & 8 \\
\hline I don't know a useful website or app that can help me learn English. & 7 \\
\hline Some apps need big space. & 6 \\
\hline I find it difficult to download or copy/paste content from my mobile that I like for future use. & 5 \\
\hline $\begin{array}{l}\text { When I use my mobile, I can't focus on what I am learning especially when someone sends me a } \\
\text { message on WhatsApp or Facebook. }\end{array}$ & 5 \\
\hline Sometimes it is difficult to follow the instructions or there are no instructions. & 4 \\
\hline
\end{tabular}

\section{Discussion}

The goal of this study was to examine undergraduate students' attitudes towards using Mobile Learning to learn English. A survey was distributed to different students representing different universities, gender, 
O.Omari, S.Bourekkadi, K.Slimani, S.Khoulji, M.L. Kerkeb. Investigating Undergraduate Students' Attitudes Towards English Mobile Learning-A Case Study of Moroccan University Students. Transactions on Machine Learning and Artificial Intelligence, Vol 5 No 4 August (2017); p: 381-394

ages, levels, and departments. Additionally, some interviews were carried out to better understand students' attitudes and the barriers that prevent them from using Mobile technology to learn English or enhance their English skills.

In general, the overall average score of students' attitudes towards learning English via M-learning $(M=3.80)$ shows that students have positive attitudes. This is to say that students agree that $M$-learning is a useful tool to learn English. These results were in conformity with other findings of other studies conducted in different countries revealing the positive attitudes of students towards Mobile Learning [14, 17-19]. In terms of items, we notice that the first item about the usefulness of M-learning to learn English was the highest $(M=4.14)$ followed by item number 10 about the helpfulness of $M$-learning in the development of the English learning process $(M=4.07)$. It is clear here that both items have got the highest scores. This means that students see M-learning as a tool that can help them enhance and develop their English learning skills. On the contrary, the 6th item about supporting communication with instructors was the lowest with regard to the overall average scores $(M=3.15)$. When we compare this item with items number 1 and 2, we notice that there is a big difference between them. For instance, the 2 nd item which is also about the opportunities that M-learning provide to communicate with colleagues ( $M=3.97)$ has a higher score than the 6th item which falls in the same category of communication. Thus, we can conclude that there maybe a problem concerning students' attitudes towards communication with instructors using M-learning.

Concerning the differences of students' attitudes to learn English using mobile learning in terms of gender and age, the results confirmed that there are no significant differences. This means that students' attitudes are equal and that gender or age does not affect their attitude to learn English via M-learning. On the other hand, a slight difference was found between students' attitudes overall score in terms of level of education. First year students' score was higher than second and third year; however, this cannot be considered as a significant difference. Meanwhile, in terms of major, the results demonstrated that students from the departments of English, physics, and French scored higher than students from the other departments. In fact, it sounds reasonable for students from the department of English to have a higher score because English is their major. However, we can say that this is a positive result because there isn't much research that tackles attitudes of students from the department of English in Morocco. Meanwhile, it is very important to highlight the score of students from the department of physics $(M=3.95)$ concerning their attitudes towards M-learning to learn English, especially because we know that English is not included in undergraduate programs at faculties of science such the case in Fez. Hence, we suggest that this result should be taken into consideration for practitioners and people in power to include English in all undergraduate levels and in all faculties without any exception.

Besides, the results revealed that most students own a smartphone and can access internet. This can be considered as a good result, especially because we are in an age of technology. Similarly, most students were found to own a smartphone with an Android or iOS operating system. Meanwhile, the results displayed that there is a difference between students' attitudes towards learning English using M-learning in terms of the used operating system. Students who use Android or iOS displayed higher attitudes than the others. Similarly, students who access internet via both Wi-Fi and 3G/4G displayed also a high level of attitude compared with those who access internet via 3G/4G only, Wi-Fi only, or those who don't have 
access to internet. These results show that the way used to access internet and the operating system can affect students' attitudes towards learning English using M-learning. Thus, we can say that students who always have access to internet (via Wi-Fi and 3G/4G) may experience higher attitudes towards learning English via M-learning. Similarly, students who own an Android or iOS operating system may have higher attitudes than others using other operating systems. This is maybe due to the fact of those operating systems features and their popularity in Morocco and worldwide. This can be also due to the ease of use and the richness of the available applications in the play stores of those two operating systems.

On the other hand, results for the fourth research question demonstrated that the most frequently used things that a student use are social networking 31\%, instant messaging $28 \%$ and listening to music $14 \%$. However, we notice that in terms of students' attitudes towards English M-learning, students who declared that accessing their emails was among the most things they frequently use scored higher than the others. Thus, we can say that students who access their emails frequently may have more attitudes to learn English via M-learning. Additionally, the use of emails is considered as part of the learning process when it is linked with formal learning. Many studies revealed the effectiveness of emails use to facilitate class activities [20-22] and collaborative work [23]. Moreover, other studies [24, 25] confirmed that email use enhances students' attitudes and interest towards the learning process.

Meanwhile, more focus should be on enhancing students M-learning attitudes towards communication with instructors. More research should be carried out to examine teachers' attitudes towards the use of technology, especially because evidence $[26,27]$ revealed that teachers' positive attitudes towards the use of technology help them integrate technology to support the learning process. That way, communication between students and instructors via technology will be enhanced.

With regard to qualitative findings, we can say that the results provided significant and useful information that could help understand students' attitudes and perceptions towards using M-learning to learn English. Meanwhile, it is very essential to highlight students' awareness about the importance of English nowadays. All students provided positive comments and ensured that learning English is crucial. On the other hand, the obtained results for the second question displayed that the majority of students consider M-learning a useful tool to learn English. This finding confirms the results obtained from the scale in this study. However, we should not forget that other students need the support of their teachers to help them find useful materials that could be beneficial to learn English through the mobile. Thus, teachers also should be involved in this matter. Additionally, some students indicated that they are easily distracted when they use their mobiles as a tool of learning. This may be because they do not link learning activities with the use of mobile devices [28]. Also, some students may be easily disturbed because learning the language is not a priority for them or because they think of the mobile as a tool of entertainment only. As concluded by [29] (in their study investigating the experience of students while using portable devices to learn) they said that students need help to recognize the value of portable devices in learning, and particularly mobile learning.

Findings of the third question of the qualitative data confirmed again the findings of the used scale and also the previous question. Most interviewed students displayed positive feelings about using the mobile to learn English. They also confirmed that mobile learning is an effective way of learning English which is quick, easy, and enjoyable. On the other hand, results obtained from the last question of the qualitative data displayed some important barriers that disturb and prevent students from using M-learning frequently. As mentioned in the result section, the interviewed students declared that bad network is 
O.Omari, S.Bourekkadi, K.Slimani, S.Khoulji, M.L. Kerkeb. Investigating Undergraduate Students' Attitudes Towards English Mobile Learning-A Case Study of Moroccan University Students. Transactions on Machine Learning and Artificial Intelligence, Vol 5 No 4 August (2017); p: 381-394

among the most obstacles that prevent them from using M-learning frequently. That is why some of them added that apps lacking the offline mode are sometimes useless. This is due to the fact that most mobile apps that support the offline mode provide limited content. Meanwhile, the findings displayed the importance of providing a feedback feature and a placement test for language learners. In addition, an important number of participants declared that the design and interfaces may stand as obstacles for them from using M-learning. In fact, these findings would be of great importance for mobile apps and websites designers. Thus, it is important to take these obstacles into consideration while developing a website or an application for language learning purposes.

\section{Conclusion}

In general, this study examined the attitudes and perceptions of undergraduate students towards learning English using M-learning. The study was conducted in several universities in Morocco and participants represented different departments and cities. Quantitative and qualitative data were carried out to understand how students perceive the use of their mobiles to learn English. The analysis of students' attitudes indicated that they have positive attitudes towards the use of M-learning as a tool of learning English. No big differences were found for students' attitudes in terms of gender, age, and level of education. Only a tenuous difference was found within students' major, operating system and network used. Meanwhile, the study revealed that students who check their emails frequently via mobile were found to have higher attitudes towards learning English via M-learning than the others. Additionally, the analysis of the findings displayed that students are aware of the importance of English and that they have positive feelings towards the use of M-learning to enhance their English language learning. Meanwhile, this study provided some of the obstacles that may prevent or make students hesitate to use M-learning. These findings will enrich the available literature and may be of great benefit for practitioners as well as websites and mobile applications programmers in the future.

The limitation of this study is that it was conducted in English. The survey was administered in English and also the interviews were carried out using English, except for some cases when some explanations were needed to be done using the mother tongue (Moroccan dialect). Another limitation is that this study was not conducted in all Moroccan public universities, so the results should not be generalized. Meanwhile, the findings of this study could have important implications for teachers, institutions, programmers, and learners who would like to learn English through their mobiles. The next step should be the integration of mobile learning in university classrooms using some local applications that are supported by the Moroccan institutions and universities. Future research should focus on identifying students' interest and preparedness to participate in English M-learning. Moreover, correlations should be carried out between students' attitudes towards English M-learning and the things they use most on their mobiles. In addition, more research is needed about teachers' attitudes and perceptions towards using and integrating $M$ learning in their English teaching courses. 


\section{ACKNOWLEDGMENT}

We are very grateful to all students who agreed to participate in this study. Their willingness to give their time so generously has been very much appreciated. We would like also to express our sincere thanks to CNRST Morocco.

\section{REFERENCES}

[1] J.Traxler, Defining mobile learning. in IADIS International Conference Mobile Learning. Qawra, Malta, pp 261-266, 2005.

[2] A. Herrington, and J. Herrington, Authentic mobile learning in higher education, in AARE 2007 International Educational Research Conference. Association for Research in Education: Fremantle, Western Australia, 2007.

[3] J.-H.Valk, A.T. Rashid, and L. Elder, Using mobile phones to improve educational outcomes: An analysis of evidence from Asia.11(1): p. 24, 2010.

[4] C. O'Malley, et al., Guidelines for learning/teaching/tutoring in a mobile environment, 2005.

[5] J. Traxler, Defining, Discussing and Evaluating Mobile Learning: The moving finger writes and having writ.The International Review of Research in Open and Distributed Learning, 8(2) 2007.

[6] D. Najima, and A. Rachida, An Adaptation of E-learning Standards to M-learning. International Journal of Interactive Mobile Technologies. 2(3): p. 11-16, 2008.

[7] J.Gikas, and M.M. Grant, Mobile computing devices in higher education: Student perspectives on learning with cellphones, smartphones \& social media. The Internet and Higher Education. 19: p. 18-26,2013.

[8] N.L.Beddall-Hill, and J. Raper, Mobile devices as 'boundary objects' on field trips. Journal of the Research Center for Educational Technology. 6(1): p. 28-46,2010.

[9] C. Evans, The effectiveness of m-learning in the form of podcast revision lectures in higher education. Computers \& Education. 50(2): p. 491-498,2008.

[10] M. Lu, Effectiveness of vocabulary learning via mobile phone. Journal of Computer Assisted Learning. 24(6): p. 515-525,2008.

[11] P. Thornton, and C. Houser, Using mobile phones in English education in Japan. Journal of Computer Assisted Learning. 21(3): p. 217-228, 2005.

[12] M. Al-Emran, H.M. Elsherif, and K. Shaalan, Investigating attitudes towards the use of mobile learning in higher education. Computers in Human Behavior. 56: p. 93-102,2016.

[13] S.S. Oyelere, J. Suhonen, S.A. Shonola, \&M.S. Joy, Discovering students mobile learning experiences in higher education in Nigeria. in 2016 IEEE Frontiers in Education Conference (FIE). 2016. 
O.Omari, S.Bourekkadi, K.Slimani, S.Khoulji, M.L. Kerkeb. Investigating Undergraduate Students' Attitudes Towards English Mobile Learning-A Case Study of Moroccan University Students. Transactions on Machine Learning and Artificial Intelligence, Vol 5 No 4 August (2017); p: 381-394

[14] F.N. Al-Fahad, Students' attitudes and perceptions towards the effectiveness of mobile learning in King Saud University, Saudi Arabia. TOJET: The Turkish Online Journal of Educational Technology. 8(2), 2009.

[15] N.Cavus, and D. Ibrahim, m-Learning: An experiment in using SMS to support learning new English language words. British Journal of Educational Technology. 40(1): p. 78-91,2009.

[16] R.M. Jaradat, Students' Attitudes and Perceptions towards using m-learning for French Language Learning: A case study on Princess Nora University. Int. J. Learn. Man. Sys. 2(1): p. 33-44,2014.

[17] L.E.S.de Montes, and C.L. Gonzales, Been There, Done That: Reaching Teachers Through Distance Education [*]. Journal of Technology and Teacher Education. 8(4): p. 351-351,2000.

[18] G. Lawrence, The Use of E-mail as a Tool to Enhance Second Language Education Programs: An Example from a Core French Classroom. Canadian Modern Language Review. 58(3): p. 465-472,2002.

[19] D.M. Poole, An email activity: preservice teachers' perceptions of authenticity. Journal of Technology and Teacher Education. 8(1): p. 13-28,2000.

[20] J. Grünberg, and A. Armellini, Teacher collegiality and electronic communication: A study of the collaborative uses of email by secondary school teachers in Uruguay. British Journal of Educational Technology. 35(5): p. 597-606,2004.

[21] T.L.Clingerman, and J.M. Bernard, An Investigation of the Use of E-Mail as a Supplemental Modality for Clinical Supervision. Counselor Education and Supervision. 44(2): p. 82-95,2004.

[22] P. Boxie, Making a cyber literacy connection from the storage room to the college room. Reading Horizons. $45(2)$ : p. 127,2004 